\title{
SARS-CoV-2 Fears Green: The Chlorophyll Catabolite Pheophorbide A Is a Potent Antiviral
}

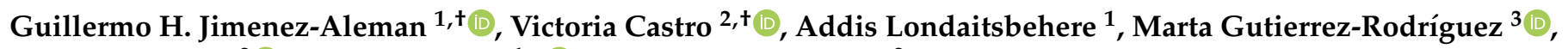 \\ Urtzi Garaigorta $^{2}{ }^{(1)}$, Roberto Solano ${ }^{1, *} *$ and Pablo Gastaminza ${ }^{2, *}$ \\ 1 National Centre for Biotechnology (CNB-CSIC), Department of Plant Molecular Genetics, \\ 28049 Madrid, Spain; gh.jimenez@cnb.csic.es (G.H.J.-A.); addislonda@yahoo.es (A.L.) \\ 2 National Centre for Biotechnology (CNB-CSIC), Department of Cell \& Molecular Biology, \\ 28049 Madrid, Spain; vcastro@cnb.csic.es (V.C.); ugaraigorta@cnb.csic.es (U.G.) \\ 3 Medicinal Chemistry Institute (IQM-CSIC), Department of Biomimetics for Drug Discovery, \\ 28006 Madrid, Spain; mgutierrez@iqm.csic.es \\ * Correspondence: rsolano@cnb.csic.es (R.S.); pgastaminza@cnb.csic.es (P.G.) \\ + These authors contributed equally to the work.
}

check for

updates

Citation: Jimenez-Aleman, G.H.;

Castro, V.; Londaitsbehere, A.;

Gutierrez-Rodríguez, M.; Garaigorta,

U.; Solano, R.; Gastaminza, P.

SARS-CoV-2 Fears Green: The

Chlorophyll Catabolite Pheophorbide A

Is a Potent Antiviral. Pharmaceuticals

2021, 14, 1048. https://doi.org/

$10.3390 /$ ph14101048

Academic Editor: Daniela De Vita

Received: 21 August 2021

Accepted: 12 October 2021

Published: 15 October 2021

Publisher's Note: MDPI stays neutral with regard to jurisdictional claims in published maps and institutional affiliations.

Copyright: (c) 2021 by the authors. Licensee MDPI, Basel, Switzerland. This article is an open access article distributed under the terms and conditions of the Creative Commons Attribution (CC BY) license (https:// creativecommons.org/licenses/by/ $4.0 /)$.

\begin{abstract}
SARS-CoV-2 pandemic is having devastating consequences worldwide. Although vaccination advances at good pace, effectiveness against emerging variants is unpredictable. The virus has displayed a remarkable resistance to treatments and no drugs have been proved fully effective against COVID-19. Thus, despite the international efforts, there is still an urgent need for new potent and safe antivirals against SARS-CoV-2. Here, we exploited the enormous potential of plant metabolism using the bryophyte Marchantia polymorpha L. and identified a potent SARS-CoV-2 antiviral, following a bioactivity-guided fractionation and mass-spectrometry approach. We found that the chlorophyll derivative Pheophorbide a (PheoA), a porphyrin compound similar to animal Protoporphyrin IX, has an extraordinary antiviral activity against SARS-CoV-2, preventing infection of cultured monkey and human cells, without noticeable cytotoxicity. We also show that PheoA targets the viral particle, interfering with its infectivity in a dose- and time-dependent manner. Besides SARS-CoV-2, PheoA also displayed a broad-spectrum antiviral activity against enveloped RNA viral pathogens such as $\mathrm{HCV}$, West Nile, and other coronaviruses. Our results indicate that PheoA displays a remarkable potency and a satisfactory therapeutic index, which together with its previous use in photoactivable cancer therapy in humans, suggest that it may be considered as a potential candidate for antiviral therapy against SARS-CoV-2.
\end{abstract}

Keywords: Pheophorbide a; COVID-19; SARS-CoV-2; chlorophyll; liverwort; Marchantia polymorpha

\section{Introduction}

The pandemic caused by the severe acute respiratory syndrome coronavirus 2 (SARSCoV-2) is having devastating consequences, with more than $229 \mathrm{M}$ infected people and over 4.7M deaths worldwide (https: / / covid19.who.int/, accessed on 25 September 2021). Besides the humanitarian cost, this pandemic carries a tremendous negative economic impact, a huge challenge for any government to overcome. The coronavirus disease 2019 (COVID-19), the respiratory illness caused by SARS-CoV-2 (Genus Betacoronavirus; Subgenus Sarbecovirus), has displayed a remarkable resistance to treatments and no drugs have been proved fully effective against the virus. Moreover, the COVID-19 pandemic has made evident the need for a global strategy to fight similar situations that may appear in the future.

Current efforts to eradicate COVID-19 are focused on the development of vaccines and the search for antiviral lead compounds, mainly repurposing of existing drugs. Although the vaccination campaign seems to advance at good pace, its effectiveness against some of the present and future strains of SARS-CoV-2 is hard to predict due to the existence of 
different strains that could drastically reduce the vaccine efficiency [1]. In addition, the best anti-COVID-19 drugs approved so far (e.g., Remdesivir (RMDV), Favipiravir or its derivative Avifavir), have shown only a mild effect against the virus, slightly reducing hospitalization time of patients [2]. Other treatments, such as Chloroquine and Hydroxychloroquine, appear to help at least a subgroup of patients, but the possible negative side effects of these drugs remain under investigation [3]. Although, some compounds (e.g., Aplidin, Mefloquine, Nelfinavir, Protoporphyrin IX and Verteporfin) have shown potential on in vitro assays, and some of them also in animal models [4-6], there is an urgent need for new potent and safe antivirals against SARS-CoV-2. Noteworthy, new pathogens, including viruses, are expected to emerge in coming decades, which puts an enormous pressure on society in order to be ready to fight back future pandemics with the proper chemical, biological, and engineering tools, including effective new antivirals.

For centuries, medical needs of society have been widely covered by plants, which have an extremely rich metabolism that provides them with a wide repertoire of chemical weapons to cope with environmental biotic stresses, including viruses $[7,8]$. Originally recognized by traditional medicine, plants are the main source of compounds used today in pharmacology, from salicylates (from Salix sp.) to current anticancer drugs (e.g., Vinblastine and Vincristine from Vinca sp., or Taxol and Paclitaxel from Taxus baccata. L), simply to cite a few successful examples $[9,10]$. Therefore, the identification of new plant sources of enzymatic variants and metabolites is essential to the discovery of new drugs and their optimization by metabolic engineering. Aromatic and exotic vascular plants are commonly studied in order to identify pharmacologically interesting compounds. In contrast, the metabolic richness of bryophytes (non-vascular plants including mosses, liverworts and hornworts) has been little explored. Bryophytes are rarely attacked by pathogens (fungi, bacteria, viruses) or herbivores (insects, snails, mammals) in their natural habitats, which indicates that they are well protected by a potent arsenal of secondary defense metabolites. However, studies on their chemical constituents have been neglected until recently [11]. Indeed, only around $5 \%$ of bryophyte species have been metabolically explored, and results have shown an enormously rich diversity of secondary metabolites, particularly in liverworts [12]. Strikingly, more than 1600 terpenoids have been reported in liverworts, whereas only about 100 terpenoids have been identified in the medicinal plant Cannabis sativa L. [11-13]. More importantly, several liverwort species of the order Marchantiales, including Marchantia polymorpha L., produce terpenoids and bisbibenzyls with enormous potential for pharmaceutical applications since they show remarkable antimicrobial, antioxidant, cytotoxic, anticancer and antiviral (anti-HIV) activities [11-16]. Therefore, we made use of our vast experience in virology and Marchantia's hormonal signaling and secondary metabolism in order to explore this plant's potential as a source of antiviral metabolites, particularly, against the SARS-CoV-2 virus.

In this study, we employed a set of Marchantia wild type plants, and signaling and metabolic mutants to systematically study the pharmacological potential of this liverwort. We found that total extracts from all the plants displayed a remarkable antiviral activity against SARS-CoV-2. Using a bioactivity-guided chromatographic approach, in addition to mass-spectrometry (MS), we identified the antiviral metabolite as Pheophorbide a (PheoA), a porphyrin chlorophyll derivative very similar to animal Protoporphyrin IX, also described as a strong antiviral [6]. We also found that PheoA has a broad-range antiviral activity against enveloped RNA viruses and acts as a virucidal by directly acting on the viral particle. Furthermore, PheoA's antiviral activity is additive to that of RMDV; this places PheoA (with very low toxicity) as a suitable candidate for antiviral therapy against SARS-CoV-2. 


\section{Results}

\subsection{Crude Extracts of M. polymorpha Show Anti-SARS-CoV-2 Activity}

In order to explore for the presence of anti-SARS-CoV-2 metabolites in M. polymorpha, we prepared crude extracts of two different $M$. polymorpha subspecies (subsp. ruderalis from Japan and subsp. polymorpha, from Spain). The anti-SARS-CoV-2 activity of the resulting crude extracts was tested in Vero E6 cell monolayers infected with the SARS-CoV-2 NL2020 strain (Figure 1A). Infection was carried out at a multiplicity of infection (MOI) of 0.001 for $72 \mathrm{~h}$. In the absence of antiviral activity, SARS-CoV-2 infection triggers cell death of Vero E6 cells and results in loss of cell biomass in the well, which is readily visualized as a strong reduction in crystal violet staining (DMSO, Figure 1A). Treatment of the cells during infection with RMDV (positive control), the only clinically approved antiviral for treatment of COVID-19 patients, protected the cell monolayers down to its reported $\mathrm{EC}_{50}$ of $1.5 \mu \mathrm{M}$ (Supplementary Figure S1). Thus, protective activity may be used as a rapid qualitative surrogate assay to facilitate identification of substances with antiviral potential [17].
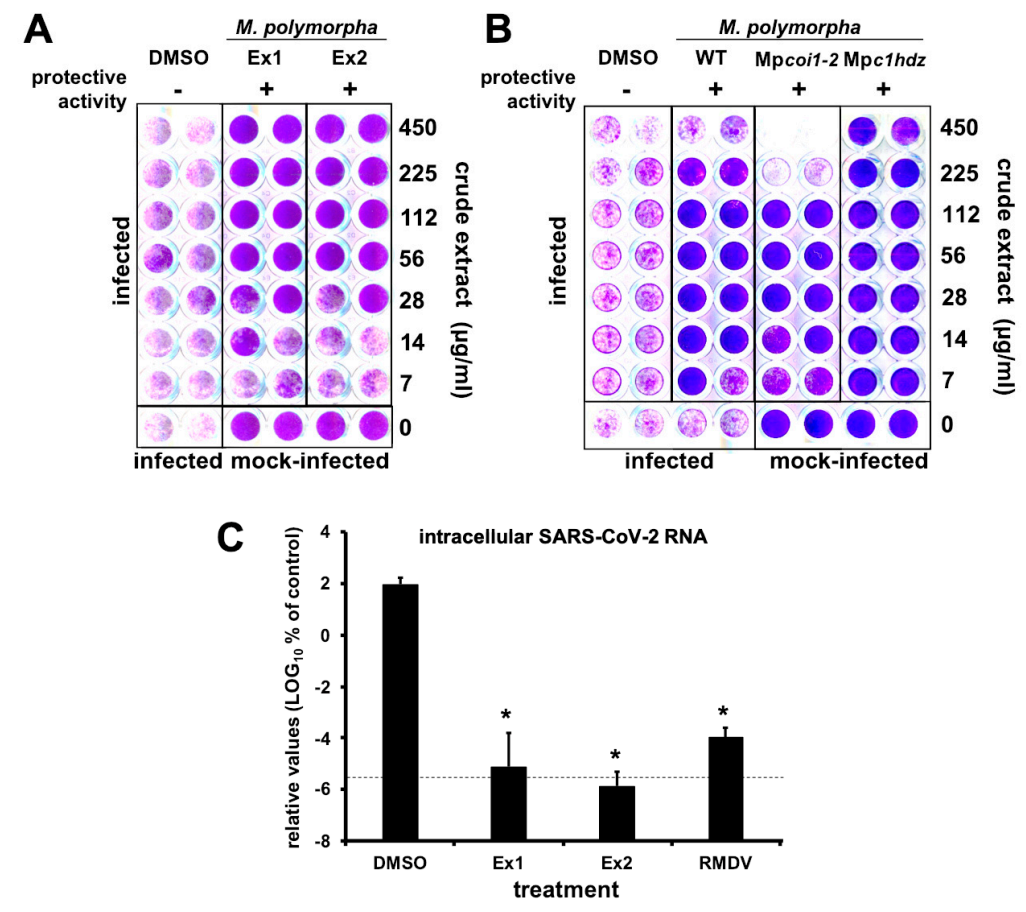

Figure 1. M. polymorpha extracts interfere with SARS-CoV-2-induced cytopathic effect and virus propagation. (A,B) Vero E6 cells were inoculated with SARS-CoV-2 (MOI = 0.001) in the presence of serial 2-fold dilutions of crude extracts from (A) two different $M$. polymorpha ecotypes, ruderalis (Ex1) and polymorpha (Ex2) or (B) WT, Mpcoi1-2 or Mpc1hdz Marchantia plants, incubated for $72 \mathrm{~h}$, time after which they were fixed and stained with a crystal violet solution. Mock-infected cells were used as the control of the integrity of the cell monolayer. Images show a representative experimental plate comparing M. polymorpha extracts with vehicle (DMSO)-treated cells. (C) Vero E6 cells were inoculated with SARS-CoV-2 $(\mathrm{MOI}=0.001)$ in the presence of vehicle $(\mathrm{DMSO}), \mathrm{RMDV}(25 \mu \mathrm{M})$ or a $100 \mu \mathrm{g} / \mathrm{mL}$ dilution of crude extracts. Uninfected samples were used as the control (mock). Total RNA was extracted $72 \mathrm{~h}$ post-infection and subjected to RT-qPCR to determine viral load. The dotted line indicates the limit of detection of the assay. Normalized viral RNA levels are shown as percentage of the viral RNA found in vehicle-treated cells. Data are shown as mean $( \pm S D)$ of three biological replicates. Statistical significance was estimated using one-way ANOVA and a Dunnet's post hoc test $\left({ }^{*} p<0.05\right)$.

Treatment of cell cultures with a broad range of concentrations of Marchantia crude extracts resulted in cell protection against virus-induced cytopathic effect without any signs of cytotoxicity at the assayed concentrations (Figure 1A, Ex1 and Ex2), suggesting the presence of one or more Marchantia metabolites with strong antiviral activity. 


\subsection{Marchantia Extract Bioactivity Depends on Plant's Primary Metabolism}

Before isolation of active compound(s) and quantitation of antiviral activity of the bioactive metabolite(s), we explored whether the putative antiviral metabolite(s) could belong to plant's secondary metabolism. Jasmonates (JAs) are a family of oxylipinderived phytohormones regulating many aspects of plant development and growth; as well as mediating defense responses through transcriptional activation of the secondary metabolism, which includes several classes of compounds such as alkaloids, terpenoids and flavonoids [18-20]. In Marchantia, secondary metabolites accumulate in specific organelles named oil bodies (OB), which are confined to scattered idioblastic OB cells distributed throughout the thallus [21]. Therefore, we tested extracts from M. polymorpha WT, Mpcoi1-2 [impaired in dn-OPDA perception, the active jasmonate in Marchantia [19], thus, in defense metabolite induction], and Mpc1hdz plants (impaired in OB formation; MpC1HDZ is a transcription factor required for $\mathrm{OB}$ cells differentiation). Mpc1hdz mutants render plants defective in secondary metabolites, thus, susceptible to herbivory and microbes [22]. Although some differential cytotoxicity was observed in the different plants at high extract concentrations, likely due to the presence of different metabolites in the extracts, all tested Marchantia extracts showed clear protective activity below cytotoxic doses (Figure 1B), suggesting that the active antiviral is present in all three plants and should not belong to the plants's secondary metabolism. Indeed, data in Figure 1B suggests that the activity of extracts is due to the presence of a metabolite (or metabolites) that is constitutively synthesized and/or derived from the plant's primary metabolism. Remarkably, regulation of primary metabolism is achieved in all plants by very similar conserved metabolic pathways $[23,24]$. To strengthen this hypothesis, we tested crude extracts of several plant species (sweet amber (Hypericum androsaemum L.), fern (Blechnum spicant (L.) Sm.), nettle (Urtica dioica L.), moss (Physcomitrium patens (Hedw.) Mitt.), tobacco (Nicotiana benthamiana Domin) and thale cress (Arabidopsis thaliana (L.) Heynh.) for their capability of providing protection to Vero E6 cells against the SARS-CoV-2 virus and showed clear protection in most cases (Supplementary Materials Figure S2), further supporting the notion that the bioactive molecule(s) correspond to plant primary metabolism (Figure 1B).

Given that potential antiviral activity had been identified by an indirect, qualitative readout, we set out to define if Marchantia extracts were indeed capable of interfering with viral spread in cell culture by determining viral load after virus spread in a multiple cycle infection experiment. Thus, Vero E6 cells were inoculated at MOI of 0.001 in the presence of control-solvent, RMDV $(25 \mu \mathrm{M})$ and Marchantia extracts from Figure 1A $(\sim 100 \mu \mathrm{g} / \mathrm{mL})$. Viral RNA load, which in this experimental setup represents the degree of virus propagation, was determined $72 \mathrm{~h}$ post infection by RT-qPCR (Figure 1C). In the vehicle control (DMSO), viral RNA accumulated six orders of magnitude above the assay limit of detection (Figure 1C), whereas the viral RNA was undetectable in samples treated with the antiviral RMDV. Importantly, in samples treated with Marchantia extracts, the viral RNA levels were comparable to those observed upon RMDV treatment, that is, close to the assay's detection limit (Figure 1C), suggesting the presence of at least one antiviral compound that strongly prevented SARS-CoV-2 infection and/or spread and, thus, reduced virus-induced CPE (Figure 1).

\subsection{Identification of the Antiviral Metabolite}

In order to identify the bioactive metabolite(s), we followed a bioactivity-guided chromatographic fractionation of the Marchantia's WT crude extracts, which showed clear antiviral potential in previous assays. Chromatographic fractions were obtained via flash column employing a solvent polarity gradient, starting at $n$-hexane $(100 \%)$ up to AcOEt:MeOH $(4: 1, v / v)$. A total of 56 fractions were obtained; fractions of a similar composition, based on their thin layer chromatography (TLC) profiles were combined and evaluated as 12 new pooled fractions (from now on, Fractions 1 to 12, Figure 2A) to identify the fractions displaying antiviral activity. Most fractions did not show any clear protection and Fraction 6 was particularly cytotoxic (Figure 2A). Fractions 10, 11 and 12 
showed clear protective activity in the monolayer protection assay (Figure 2A), suggesting that they contain antiviral compounds. To directly confirm their antiviral activity, the viral antigen load reduction after inoculation of cell cultures with SARS-CoV-2 $(\mathrm{MOI}=0.01)$ was measured. In this experimental setup, viral antigen accumulates as a consequence of virus propagation and can be quantitated using automated immunofluorescence microscopy. Figure $2 \mathrm{~B}$ shows a dose-dependent reduction in viral antigen accumulation and the absence of cytotoxicity, as confirmed by normal cell numbers, estimated by DAPI staining and image analysis (Figure 2C), and cell viability studies performed in parallel in uninfected cultures by MTT assays (Figure 2B,C).

A

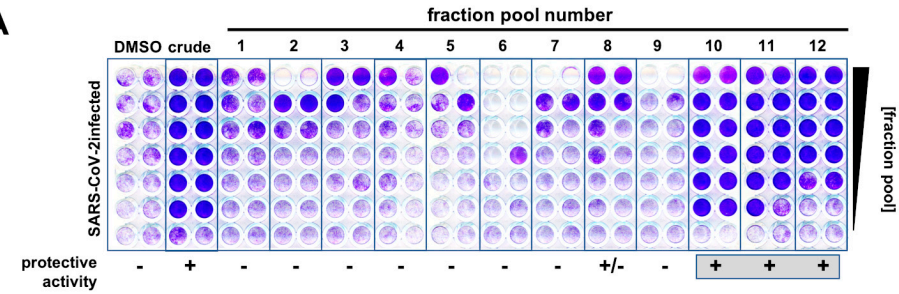

B

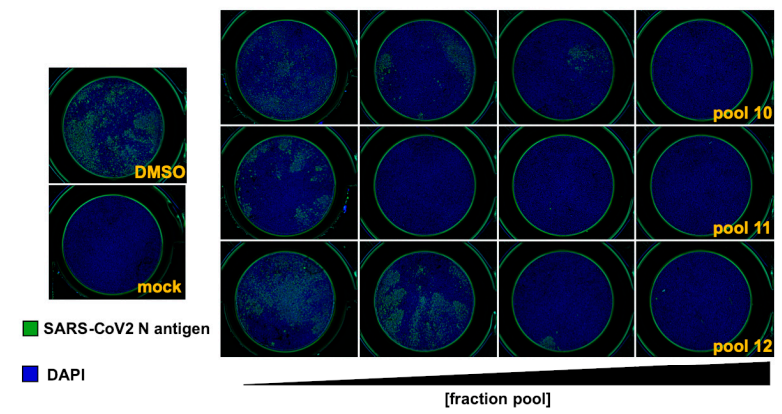

C

$\square$ infection efficiency $\square$ cell number $\square$ cell viability

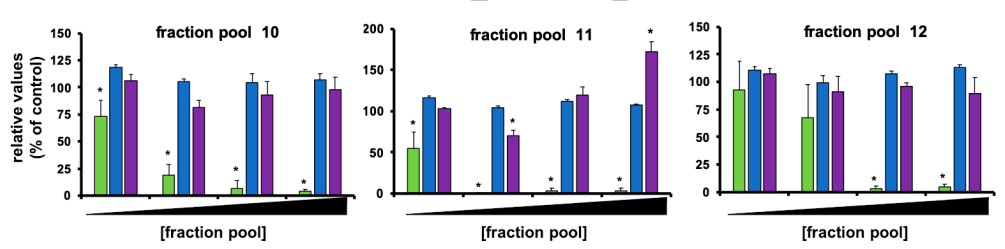

Figure 2. Extract fractionation and identification of antiviral fraction pools. (A) Vero E6 cells were inoculated with SARS-CoV-2 $(\mathrm{MOI}=0.001)$ in the presence of serial 2-fold dilutions of vehicle (DMSO), a crude Marchantia extract and the fraction pools. Inoculated cultures were incubated for $72 \mathrm{~h}$, time after which they were fixed and stained with a crystal violet solution. Mock-treated cells were used as the control of the integrity of the cell monolayer (non-infected). (B) Vero E6 cells were inoculated $(\mathrm{MOI}=0.01$ ) in the presence of serial dilution of the fractions and incubated for $24 \mathrm{~h}$ before fixation; processing for immunofluorescence microscopy and cytotoxicity assays was as described in the materials and methods section. Representative images of the fraction pool cell-based evaluation are shown. (C) Quantitation of infection efficiency, cell number and cell viability. These data are shown as average $( \pm S D)$ of three biological replicates. Statistical significance was estimated using one-way ANOVA (Dunnet's post hoc test, ${ }^{*} p<0.05$ ).

Interestingly, TLCs of the three active fractions presented red fluorescent spots (under long-wave ultraviolet light, $365 \mathrm{~nm}$; Supplementary Materials Figure S3A), which are characteristic of plant chlorophylls, but with a smaller retention factor $(\mathrm{Rf}=0.36$, AcOEt:MeOH $(9: 1, v / v))$ than that of chlorophyll $(\mathrm{Rf}=0.92)$. At this point, we suspected that the active antiviral metabolite(s) could be related to plant chlorophylls, because of (i) relative antiviral potency coincides with the relative abundance of the red fluorescent spots (Figure 2C and Supplementary Materials Figure S3) and (ii) a very weak protective activity was observed at low dilutions of fractions pools 2 and 3 (Figure 2A and Supplementary Materials Figure S3B), both containing chlorophyll. Indeed, these frac- 
tions, when re-chromatographed, yielded spots on the TLC with a Rf consistent with that observed in the active fractions 10 to 12, indicating that the active metabolite is a chlorophyll derivative (Supplementary Materials Figure S3B). It is worth mentioning that heat notably accelerated the chlorophyll decomposition into the investigated metabolite (Supplementary Materials Figure S3B).

Next, we employed preparative TLC in order to better isolate and characterize the redlight emitting metabolite. Photosynthetic metabolites were extracted from $M$. polymorpha WT and Mpc1hdz plants, and the extracts subjected to preparative TLC, to further verify that the investigated molecule is indeed a primary metabolite present both in WT and mutant Marchantia plants. Three spots showed fluorescence in the vicinity of the expected Rf; these spots where isolated, analyzed by HPLC-UV-MS and the bioactivity assayed as fractions C, $\mathrm{D}$ and $\mathrm{E}$ (Figure 3A). Similar spot concentrations were studied using a quantitative method in order to identify the molecule(s) with the strongest antiviral potential. Fraction D, which corresponded with an enrichment of compound $\mathbf{1}$ in the UV chromatograms (Figure 3C), showed the strongest antiviral activity, as compared with $\mathrm{C}$ or E (Figure 3B). Careful analysis of the MS spectra revealed a molecular formula of $\mathrm{C}_{35} \mathrm{H}_{36} \mathrm{~N}_{4} \mathrm{O}_{5}$ for compound 1, as deduced by HR-ESI ${ }^{+}$-MS from its monoprotonated molecular ion, $[\mathrm{M}+\mathrm{H}]^{+}$, with a $m / z$ of 593.2759. The identified molecular formula (containing four nitrogen atoms), the exact mass and the characteristic red fluorescence of the compound helped to identify 1 as the chlorophyll catabolite PheoA (Figure 3C). The identity of PheoA was further confirmed by comparison with both a commercially available original standard (Santa Cruz Biotechnology, Dallas, TX, USA) and a semisynthetic sample. PheoA was obtained semisynthetically from Marchantia in good overall yield via a solvent free, thus, environmentally friendly method (Supplementary Materials Figure S4 and M\&M section).
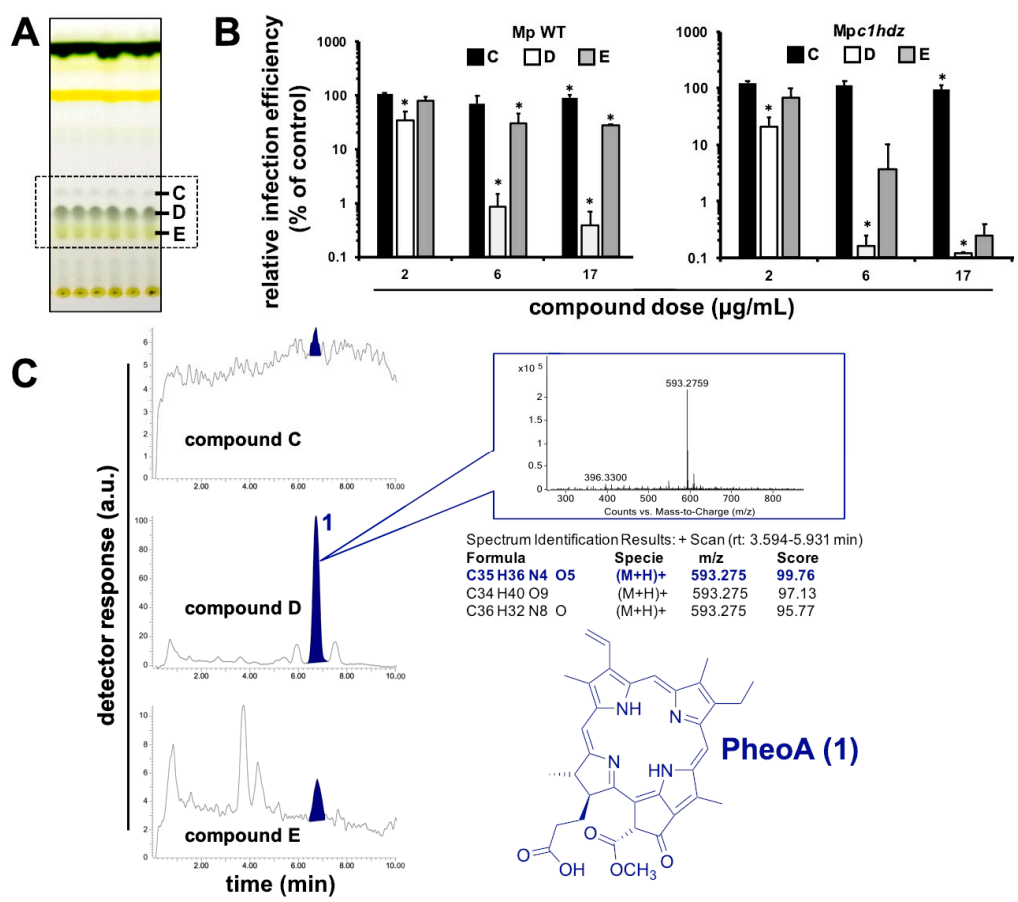

Figure 3. Identification of the main antiviral compound in Marchantia extracts. (A) Representative TLC of Marchantia WT and c1hdz extracts. Compounds C, D and E (box) were tested for their antiviral potential. (B) Vero E6 cells were inoculated $(\mathrm{MOI}=0.01)$ in the presence of the indicated compounds and incubated for $24 \mathrm{~h}$ before fixation and processing for immunofluorescence microscopy. Data are shown as average $( \pm S D)$ of three biological replicates. Statistical significance was estimated using one-way ANOVA and a Dunnet's post hoc test $\left.{ }^{*} p<0.05\right)$. (C) Representative HPLC/MS analysis (shown for WT) of fractions $\mathrm{C}, \mathrm{D}$, and $\mathrm{E}$, including exact mass determination of the antiviral candidate 1 , and its inferred chemical structure. 


\subsection{Antiviral Activity of PheoA}

To confirm the antiviral potential of PheoA, a commercially available PheoA stock solution was serially diluted and mixed with a virus stock to inoculate Vero E6 and Huh7-ACE2 cells (human hepatoma cells expressing ACE2). Cells were fixed $72 \mathrm{~h}$ postinoculation and stained with crystal violet to visualize the integrity of the cell monolayer. Figure S5 shows consistent protective capacity of PheoA above $65 \mathrm{nM}$ in both cell lines (Supplementary Materials Figure S5).

PheoA antiviral activity was further confirmed by immunofluorescence microscopyto estimate virus propagation-and an MTT assay-to evaluate compound cytotoxicity. PheoA dose-response curves demonstrate PheoA's antiviral activity against SARS-CoV-2 in Vero E6 and human lung epithelial cells (A549-ACE2 and Calu3); in all three models, no cytotoxicity was observed at the assayed doses (Figure 4A-C). This dataset was used to determine effective concentrations $\left(\mathrm{EC}_{50}\right.$ and $\left.\mathrm{EC}_{90}\right)$ and cytotoxicity indexes. The estimated $\mathrm{EC}_{50}$ and $\mathrm{EC}_{90}$ values were around $50 \mathrm{nM}$ and $100 \mathrm{nM}$, respectively, with a wide therapeutic window in all tested cell lines (Table 1)

To independently evaluate the extent to which PheoA interferes with SARS-CoV-2 infection (i.e., with viral replication), we employed RT-qPCR to determine the extracellular viral RNA load in human cells inoculated with SARS-CoV-2 (MOI $=0.001)$. In this experimental setup, RMDV ( $5 \mu \mathrm{M})$ reduced extracellular viral RNA by two orders of magnitude. Interestingly, PheoA reduced viral RNA accumulation in a dose-dependent manner after a $48 \mathrm{~h}$ incubation period (Figure 4D). These results indicate that PheoA displays a remarkable potency and a satisfactory therapeutic index and suggest that it may be considered as a potential candidate for antiviral therapy against SARS-CoV-2. Furthermore, results suggest that PheoA is a major determinant of the antiviral activity observed in crude Marchantia extracts (Figure 1). This notion is underscored by the fact that the semisynthetic PheoA (ca. $90 \%$ by HPLC-UV/Vis) showed comparable potency to crude extracts in the different cell lines (Supplementary Materials Figure S6). Nevertheless, other related chlorophyll metabolites may also contribute with antiviral activity. In fact, pyropheophorbide a (pPheoA), which was also found in antiviral fractions, was tested to verify its antiviral potential in Vero E6 cells. The pPheoA showed antiviral activity in the absence of measurable cytotoxicity with an $\mathrm{EC}_{50}$ of $185 \mathrm{nM}$ (Supplementary Materials Figure S7), suggesting that pPheoA may contribute to the overall antiviral activity of the extracts.

Table 1. Potency and cytotoxicity indexes of commercially available PheoA. Values are provided as mean and standard deviation of three biological replicates $(n=3)$.

\begin{tabular}{cccc}
\hline Cell Line & EC $_{\mathbf{5 0}}$ (nM) & EC $_{\mathbf{9 0}}$ (nM) & $\mathbf{C C}_{\mathbf{5 0}}$ (nM) \\
\hline Vero-E6 (Green Monkey) & $54 \pm 13$ & $106 \pm 16$ & $>8420$ \\
\hline A549-ACE2 (Human Lung) & $62 \pm 25$ & $201 \pm 84$ & $2600 \pm 500$ \\
\hline Calu3 (Human Lung) & $35 \pm 20$ & $98 \pm 8$ & $>8420$ \\
\hline
\end{tabular}



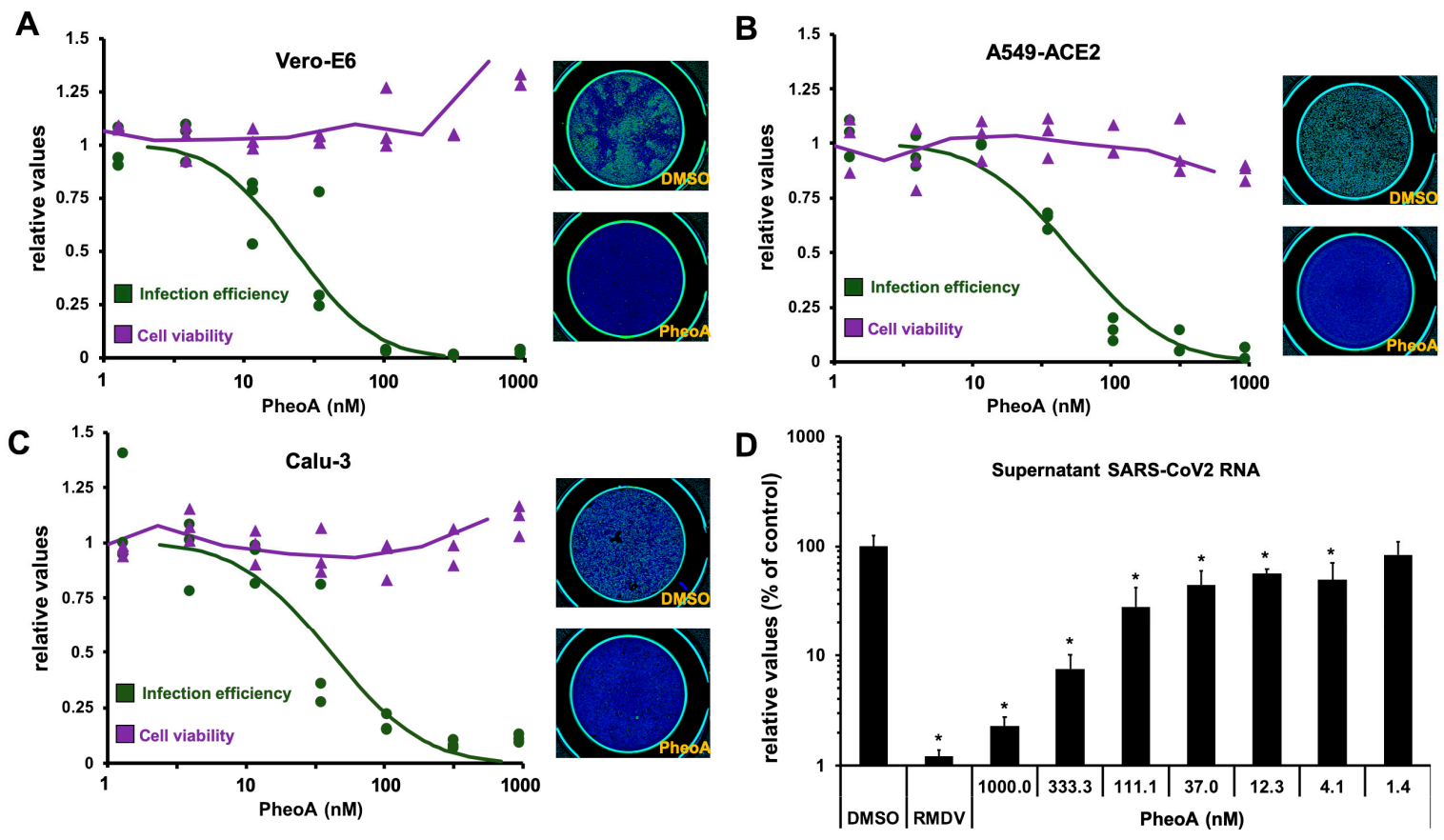

Figure 4. PheoA shows antiviral activity against SARS-CoV-2 in Vero E6 cells and human lung epithelial A549-ACE2 and Calu3 cell lines. (A-C) Commercially available PheoA was serially diluted and mixed (1:1, v/v) with SARS-CoV-2 preparations to achieve the indicated compound concentrations and a final MOI of 0.005 for (A) Vero E6 and (B) Calu3 and 0.01 for (C) A549-ACE2 cells. Cultures were incubated for $48 \mathrm{~h}$, fixed and processed for automated immunofluorescence microscopy analysis. Parallel, uninfected cultures were processed for cytotoxicity evaluation using an MTT assay. Relative infection efficiency data ( $n=3$ per dose) are shown as individual data and a PROBIT regression curve (green line) using the represented values. Cytotoxicity data $(n=3$ per dose) are shown as the individual data and a moving average trend line. (D) A549-ACE2 cells were inoculated at MOI $=0.01$ in the presence of increasing concentrations of PheoA or RMDV (5 $\mu \mathrm{M})$ and incubated for $48 \mathrm{~h}$. Samples of the supernatants were collected, heat-inactivated and directly subjected to RT-qPCR to estimate overall infection efficiency. Data are expressed as relative values compared with the vehicle (DMSO)-treated cells and are shown as the mean $( \pm \mathrm{SD})$ of three biological replicates $(n=3)$. Statistical significance was estimated using one-way ANOVA and a Dunnet's post hoc test $\left({ }^{*} p<0.05\right)$.

\subsection{Antiviral Spectrum of PheoA}

PheoA has previously been proven as an antiviral against the hepatitis $C$ virus (HCV) [25] and virucidal against herpes simplex virus (HSV) [26]. Thus, we determined the antiviral spectrum of PheoA on different enveloped RNA viruses. First, we confirmed antiviral activity against $\mathrm{HCV}$, using a surrogate model of infection by propagationdeficient, bona fide reporter virus bearing a luciferase reporter gene generated by transcomplementation (HCVtcp). Dose-response curves of the luciferase activity in HCVtcpinfected Huh7 cells indicated an $\mathrm{EC}_{50}$ of $300 \mathrm{nM}$ for PheoA against HCV (Figure 5A), very similar to the previously reported $\mathrm{EC}_{50}[25]$.

Next, we asked whether PheoA antiviral activity against SARS-CoV-2 could also be observed against other human coronaviruses such as hCoV-229E (Genus Alphacoronavirus; Subgenus Duvinecovirus), which has been associated with mild respiratory infections [27]. Huh7 cells were inoculated with a GFP reporter-expressing recombinant hCoV-229E $(\mathrm{MOI}=0.01)$ and total GFP expression in the target Huh7 cells was evaluated by automated microscopy $48 \mathrm{~h}$ post-inoculation. Similar to the results with the HCV infection model, PheoA reduced viral spread $\left(\mathrm{EC}_{50}\right.$ of $\left.128 \mathrm{nM}\right)$ while no cytotoxicity was observed (Figure 5B). Comparable results were obtained in an experimental model of infection by the West Nile Virus, a mosquito-borne zoonotic Flavivirus that may cause encephalitis in infected humans. A recombinant, di-cistronic infectious molecular clone expressing GFP in the second cistron [28] was used to inoculate Huh7 cells $(\mathrm{MOI}=0.01)$. Cells were imaged $48 \mathrm{~h}$ post infection and the degree of virus propagation was determined via automated 
microscopy; dose response curves (Figure 5C) indicated antiviral activity for PheoA with an $\mathrm{EC}_{50}$ of $64 \mathrm{nM}$ ). Finally, PheoA antiviral activity was observed against a recombinant vesicular stomatitis virus bearing a GFP reporter gene (VSV-GFP) obtaining comparable effective concentrations in Huh7 ( $\mathrm{EC}_{50} 506 \mathrm{nM}$; Figure 5D) and A549-ACE2 cells (EC 50 $578 \mathrm{nM}$; data not shown), further reinforcing the notion that PheoA is a broad-spectrum antiviral molecule with activity against all tested viruses, including SARS-CoV-2.

A

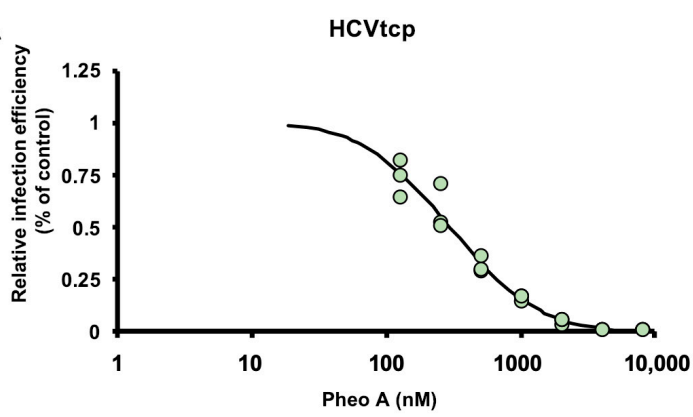

C

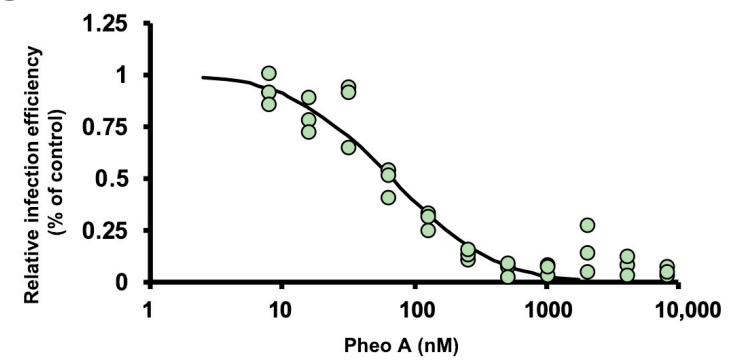

B

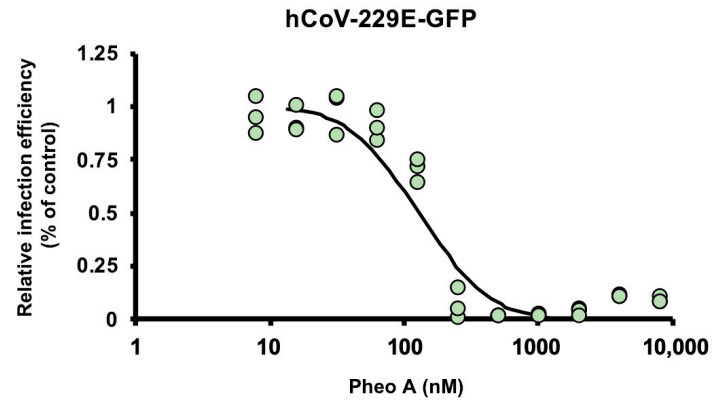

D

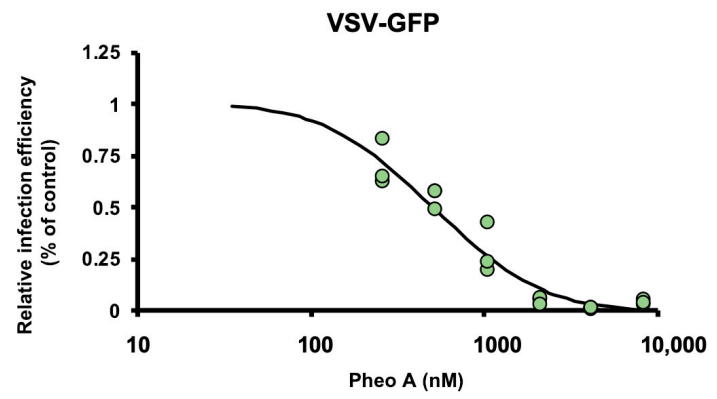

Figure 5. Antiviral spectrum of PheoA against different RNA viruses. The effectiveness of PheoA was tested against four different recombinant RNA viruses expressing reporter genes. (A) Huh7 cells were infected with HCVtcp in the presence of increasing PheoA doses and luciferase activity was determined $48 \mathrm{~h}$ post-inoculation. (B-D) Cells were inoculated in the presence of increasing concentrations of PheoA at MOI 0.01 and incubated to enable virus propagation. At the endpoint, cells were fixed and counter stained with DAPI to control for unexpected cytotoxic effects. Relative infection efficiency was estimated using automated microscopy and is expressed as percentage of the infection efficiency observed in control wells. (B) Huh7 cells were infected with hCoV-229E-GFP and fixed $48 \mathrm{~h}$ post-inoculation. (C) Huh7 cells were infected with WNV-GFP and fixed $48 \mathrm{~h}$ post-inoculation. (D) A549-ACE2 cells were inoculated with VSV-GFP and fixed $16 \mathrm{~h}$ post-inoculation. Individual replicate data are shown as green dots $(n=3)$ and the PROBIT regression curve used to estimate EC50 values is shown.

\subsection{PheoA Can Be Employed in Combination with RMDV}

Once the broad antiviral activity of PheoA has been demonstrated, we studied whether the addition of PheoA to RMDV treatment could result in a synergistic effect on viral infection. Thus, combination treatments were performed with increasing doses of PheoA and RMDV. Drugs were mixed in different proportions, combined with infectious SARS-CoV-2 $(\mathrm{MOI}=0.01)$ and the mixtures were used to inoculate Vero E6 cells. Twenty-four hours later, cells were fixed and processed to determine the infection efficiency as using immunofluorescence microscopy. Individual treatment with either compound resulted in the expected dose-dependent inhibition of virus infection, achieving the $\mathrm{EC}_{50}$ at the expected doses (2000 nM for RMDV and $40 \mathrm{nM}$ for PheoA). Increasing concentrations of PheoA improved RMDV efficacy and viceversa. However, full analysis of the combinations resulted in a synergy index close to three, indicating that the drug combination is mostly additive [29], with an area of synergy at concentrations close to the $\mathrm{EC}_{50}$ (Figure 6). These results suggest that combinations of PheoA with other antivirals may result beneficial, as it was observed by its additive effect in combination with RMDV in cell culture infection models. 
A
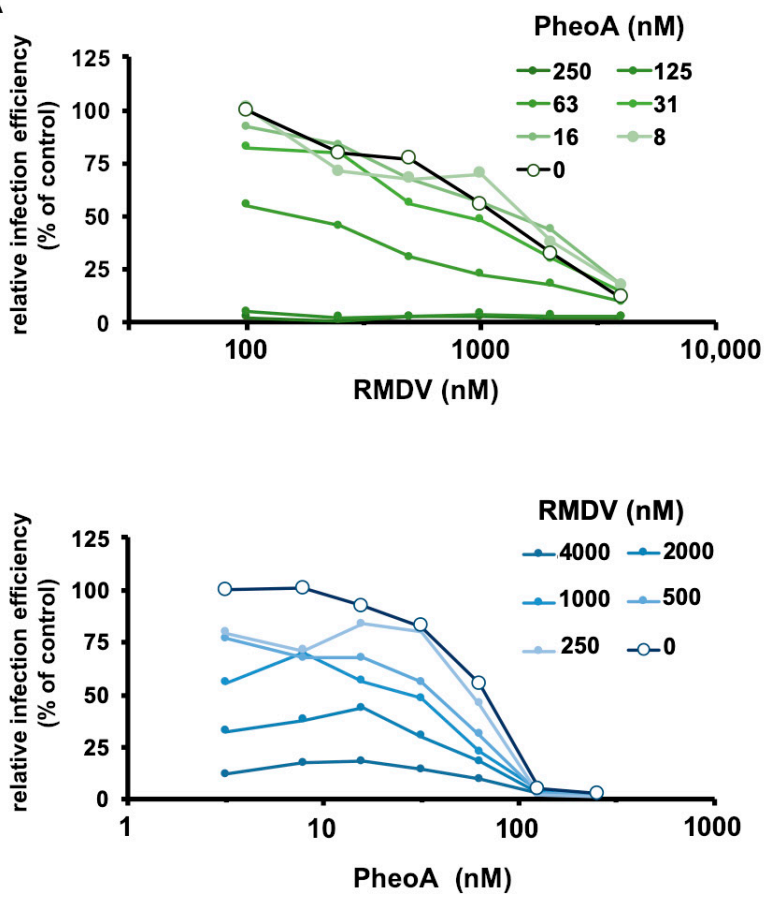

B

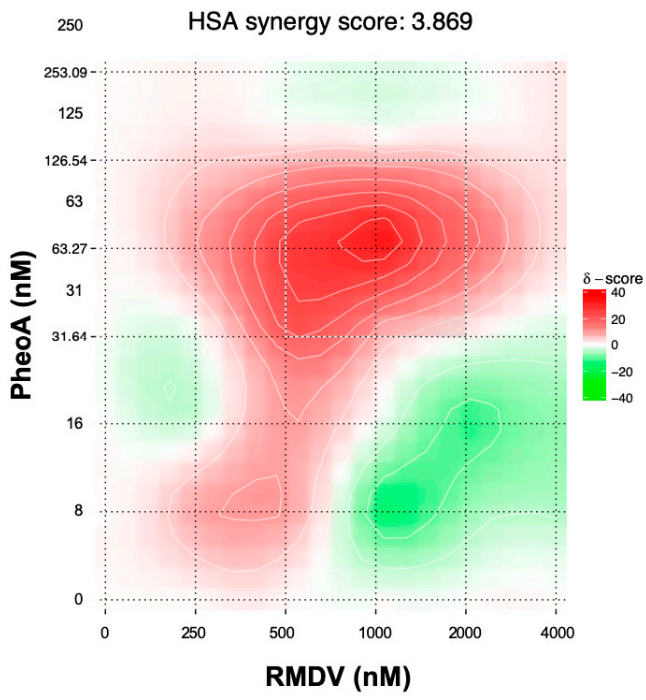

Figure 6. Combination treatment of PheoA with RMDV. Vero E6 cells were inoculated at MOI $=0.005$ in the presence of increasing concentrations of PheoA in combination with increasing doses of RMDV. Twenty-four hours post infection, cells were fixed and processed for automated immunofluorescence microscopy. Relative infection efficiency values were estimated as percentage of the values obtained in mock-treated cells. (A) Data are shown as average of two biological replicates. (B) Heatmap describing the areas of synergy within the combination treatments.

\subsection{Characterization of PheoA Mode of Action on SARS-CoV-2 Infection}

Next, antiviral efficacy of PheoA was compared when PheoA was (i) present at all times, (ii) added only during virus inoculation, or (iii) added only after virions had effectively penetrated the cells in single-cycle infection experiments $(\mathrm{MOI}=5)$. Imatinib $(15 \mu \mathrm{M})$, for which antiviral activity at the level of virus entry has previously been demonstrated [17] and RMDV were employed as the reference compounds. Infection efficiency revealed the expected antiviral activity for imatinib, RMDV and PheoA when maintained at all times in the experiment (Figure 7). RMDV was highly effective at reducing infection efficiency, as suggested by SARS-CoV-2 N protein staining, indicating that the measured signal requires viral RNA replication (Figure 7B). Imatinib showed comparable efficacy when added during the virus entry phase and greatly lost efficacy when added after virion internalization, as expected for an entry inhibitor [17]. Similar results were obtained with PheoA, inhibition was nearly identical when maintained at all times or added during viral entry, but only ca. $6 \%$ of the maximum efficacy was observed when added after virion internalization. These results suggest that PheoA is mainly acting at early stages of the infection, potentially at the level of viral entry.

In view of these results, we directly tested this hypothesis by determining the antiviral activity of PheoA in a surrogate model of infection recapitulating only aspects related with viral entry such as receptor recognition, virion internalization or membrane fusion. This system is based on reporter retroviral vectors pseudotyped with SARS-CoV-2 Spike protein (SARS2pp) or VSV glycoprotein as a control (VSVpp). Infection efficiency in the presence of antiviral molecules is determined as the relative expression values of the reporter gene, in this case a Firefly luciferase [17]. Relative infection efficiency was measured in the presence of the entry inhibitor imatinib $(15 \mu \mathrm{M})$ and antiviral doses of PheoA. As expected, imatinib selectively inhibited SARS2pp and not VSVpp entry (Supplementary Materials Figure S8). PheoA barely interfered with either of the retroviral pseudotype infection efficiencies, with 
a maximum reduction of $40 \%$ at the maximum dose (675 nM) (Supplementary Materials Figure S8). These results suggest that, while time-of-addition experiments suggest that PheoA interferes predominantly with early aspects of the infection, surrogate models of viral entry indicate that it does not interfere substantially with molecular events leading to viral entry per se.

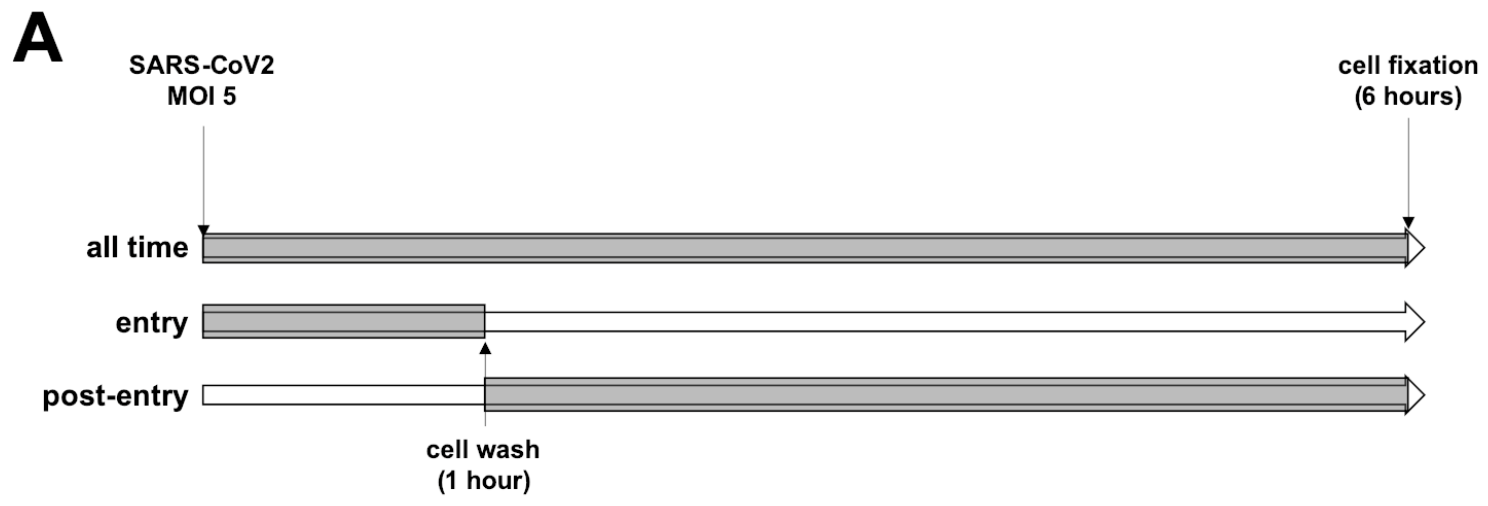

B

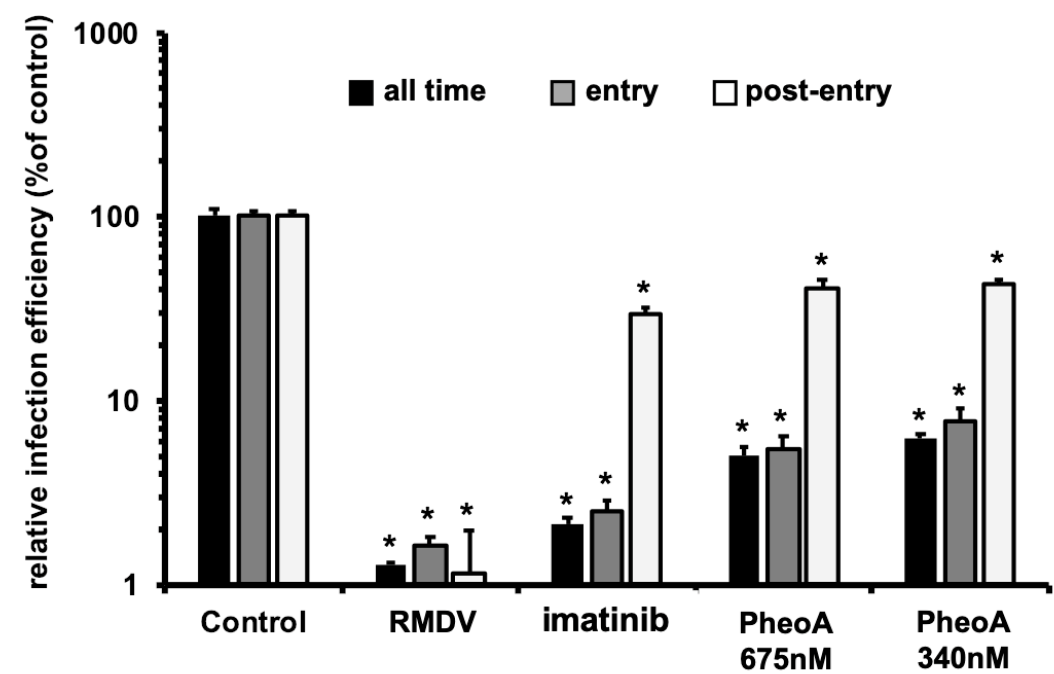

Figure 7. Time-of-addition experiments indicate that PheoA interferes with early aspects of SARS-CoV-2 infection. Vero E6 cells were inoculated at MOI = 5 in the presence (gray) or absence (white) of the indicated doses of PheoA, RMDV or imatinib as described in both the text and the scheme. Cells were incubated for $6 \mathrm{~h}$ in the presence (gray) or absence (white) before chemical fixation and processing for immunofluorescence microscopy. (A) Schematic diagram of the times where compound was present in the assay. (B) Infection efficiency is expressed as the percentage of that observed in vehicle DMSO-treated cells and is shown as average and standard deviation of three biological replicates $(n=3)$. Statistical significance was estimated using one-way ANOVA and a Dunnet's post hoc test $\left.{ }^{*} p<0.05\right)$.

PheoA irreversibly interferes with the virion infectivity in HSV and influenza infection models [30], therefore, we explored whether PheoA could be virucidal for SARSCoV-2 virions, a property that would be compatible with the observations made in the time-of-addition experiments (Figure 7). Thus, a known number of infectious particles $\left(10^{5} \mathrm{TCID}_{50} / \mathrm{mL}\right)$ were mixed with increasing doses of PheoA [14 to $\left.8420 \mathrm{nM}\right)$ ] and incubated for $30 \mathrm{~min}$ before residual infectivity titer was calculated by endpoint dilution and TCID $_{50}$ determination. The dose of PheoA was kept below its effective concentrations during the titration experiment. Figure $8 \mathrm{~A}$ shows how pre-incubation of the infectious virions with PheoA resulted in a dose-dependent reduction in the remaining virus infectivity that was statistically significant at doses above $67 \mathrm{nM}$. Next, we tested the impact of incubation time at a fixed PheoA dose (340 nM). Incubation of the virus at room temperature for up 
to $15 \mathrm{~min}$ in the presence of PheoA did not have any significant impact on virus infectivity (Figure $8 \mathrm{~B}$ ). However, longer incubation periods reduced partially ( $30 \mathrm{~min}$ ) or below detection limits (60 $\mathrm{min}$ ) SARS-CoV-2 infectivity. The fact that exposure to PheoA for less than $30 \mathrm{~min}$ does not reduce SARS-CoV-2 infectivity, testifies for the lack of interference of the diluted PheoA on viral infection efficiency. Thus, these results reveal a time- and dose-dependent reduction in virus infectivity by exposure to PheoA, suggesting that PheoA is virucidal for SARS-CoV-2 virions and that virion infectivity inactivation contributes to its overall antiviral effect.
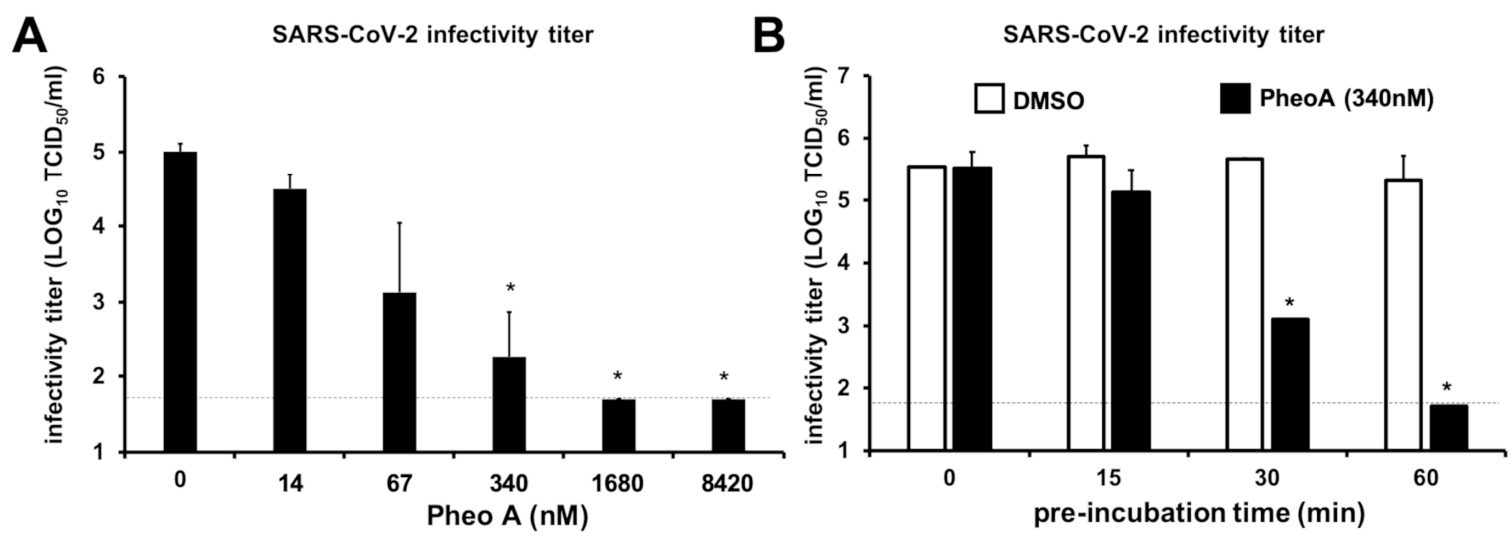

Figure 8. PheoA interferes with SARS-CoV-2 virion infectivity in a dose- and time-dependent manner. SARS-CoV-2 virus stocks were diluted to obtain $1 \times 10^{5} \mathrm{TCID}_{50} / \mathrm{mL}$ and were mixed with increasing concentrations of PheoA or the vehicle (DMSO). (A) Dose-dependent reduction in SARS-CoV-2 infectivity by PheoA. Virus-compound mixtures were incubated at room temperature for $30 \mathrm{~min}$ and were serially diluted to determine the remaining infectivity titer using endpoint dilution and determination of virus-induced cytopathic effect by crystal violet staining in Vero-E6 cells. (B) Pre-incubation time-dependent reduction in SARS-CoV-2 infectivity by PheoA. Experiments were carried out using a fixed dose of PheoA $(340 \mathrm{nM})$ and increasing pre-incubation times before serial dilution for TCID 50 determination. Values are expressed as LOG TCID $50 / \mathrm{mL}$ and shown as the average and standard deviation of three independent experiments $(n=3)$. Statistical significance was estimated using one-way ANOVA and a Dunnet's post hoc test $\left({ }^{*} p<0.05\right)$.

\section{Discussion}

Due to their metabolic richness plants have been traditionally used as source of medicines. The potential of plant metabolites in pharmacology is still far from being saturated, particularly in certain plant clades. Indeed, bryophytes (non-vascular plants) are particularly rich in specialized metabolites that are rarely found in other plant lineages [26]. Here, we explored this richness in order to find antiviral compounds against the SARSCoV-2 virus by employing an activity-guided chromatographic method; and identified PheoA as a potent antiviral, very efficient not only against SARS-CoV-2 but also against several other enveloped viruses.

The first evidence for antiviral activity of PheoA derives from observations made on HSV infection models [27]. In those initial reports, some degree of selectivity towards other viruses was reported, since adenovirus (Type VI), Japanese Encephalitis virus (JEV) or poliovirus were not affected by treatment with PheoA-enriched algal extracts [31]. Subsequent studies suggested that PheoA and pPheoA display broad-spectrum antiviral activity against enveloped viruses, including influenza A [30] and HIV [28], but not against non-enveloped viruses [30]. Ohta et al., reported that PheoA-containing preparations may display virucidal activity against HSV [32], a concept that was further supported by Bouslanu et al. [30]. Our observations support that PheoA inactivates SARS-CoV-2 virion infectivity through a virucidal mode of action. First, time-of-addition experiments indicate that early aspects of the infection are targeted by PheoA. Second, the study of viral entry using retroviral pseudotypes did not reveal any measurable antiviral activity against SARS-CoV-2 entry, suggesting that receptor recognition by the Spike protein, particle internalization and Spike-mediated fusion are not overtly affected by PheoA. Similar 
models have been used to identify key SARS-CoV-2 entry factors as well as to study antibody neutralizing activity [33,34]. Thus, inactivation of viral infectivity (virucidal activity) was tested as a possible mechanism reconciling these apparently contradicting observations. Pre-incubation of infectious SARS-CoV-2 virions with PheoA rendered the virions non-infectious in a time- and dose-dependent manner. These observations are similar to those reported by other groups in other infection models [30,32]. The virtual lack of activity of PheoA at post-entry levels may be explained by the fact that PheoA acts primarily on the viral particle, or that PheoA requires longer incubation periods to penetrate the cell and interfere with downstream steps of the virus lifecycle. Given that overall effectiveness of PheoA as virucidal is substantially stronger than during multiple cycle infection experiments, it is likely that virucidal activity is the main mechanism for interference with SARS-CoV-2 infection.

PheoA has been shown to integrate into biological membranes [35]. Thus, it is possible that PheoA could insert into the viral envelope lipid bilayer, altering its biophysical properties, or even disrupting it, thus rendering the virion non-infectious. This would explain PheoA's virucidal activity and its broad-spectrum among enveloped viruses. PheoA is a plant derived porphyrin closely related to animal porphyrins, which have been widely described as broad-spectrum virucidals (reviewed in Sh. Lebedeva et al. [36]). Virion inactivation is thought to occur through incorporation of porphyrins into the viral envelope membrane and modifying its physico-chemical properties, thus interfering with host cell recognition and fusion processes. However, porphyrins such as protoporphyrin IX display antiviral activity independently of their virucidal activity at post-entry steps and have been proposed to interfere with receptor (ACE2) recognition in SARS-CoV-2 infection models [6]. The structural resemblance between PheoA and proporphyrin IX may explain their similar antiviral properties (broad spectrum and virucidal), but, at the same time, their differences may contribute to PheoA's increased tolerability and in vivo effectiveness, an issue that has extensively been explored for different PheoA applications as photosensitizer in photodynamic therapies against cancer [31,37].

One huge advantage of PheoA is that it is readily available from plant and algae chlorophyll. PheoA is the dephytylation and demetallation product of chlorophyll $a$, processes mediated by chlorophyllase and $\mathrm{Mg}$-dechelatase, respectively [38,39]. Clorophyllase activity is favored by high temperatures $\left(60-80{ }^{\circ} \mathrm{C}\right)$ [38] and its accumulation varies throughout plant development and in stress conditions. In this study, we also exploited stress conditions (heat) that favour PheoA accumulation and PheoA was semisynthetically prepared from M. polymorpha in good overall yield.

Another advantage of PheoA is that its combination with RMDV has an additive effect with no cross inhibition in their antiviral activity, and a mild synergy. This, together with its low toxicity in vivo, represents an advantage that could be clinically exploited [40].

\section{Materials and Methods}

\subsection{Equipment and Reagents}

All solvents were of ACS quality unless stated otherwise. Commercially available PheoA was purchased from Santacruz Biotechnology ( $>90 \%$ by HPLC). A Geno Grinder Spex/SamplePrep 2010 was employed for tissue homogenization. Glass- or aluminumsupported Silica gel 60 (Merck) was used for preparative and analytical TLCs, respectively; for flash column purification, silica gel $60 \AA$, 230-400 mesh, 40-63 $\mu \mathrm{m}$ was employed. HPLC-UV-MS analysis was carried out by using a Waters Separations module Alliance e2695 system, a Waters QDa Detector Acquity QDa and a Waters Photodiode Array Detector 2996. HPLC was performed by using HPLC grade solvents and a Sunfire C18 $(4.6 \times 50 \mathrm{~mm}, 3.5 \mu \mathrm{m})$ column at $30^{\circ} \mathrm{C}$, with a flow rate of $1 \mathrm{~mL} / \mathrm{min}$ and a mobile phase gradient from 70 to 95 of $\mathrm{A}$ (formic acid $0.1 \%$ in $\mathrm{CH}_{3} \mathrm{CN}$ ) in $\mathrm{B}\left(0.1 \%\right.$ of formic acid in $\mathrm{H}_{2} \mathrm{O}$ ) for $10 \mathrm{~min}$. Electrospray in positive mode was used for ionization. The HR-MS analysis was carried out by using an Agilent 1200 Series LC system (equipped with a binary pump, an autosampler, and a column oven) coupled to a 6520 quadrupole-time of flight (QTOF) mass 
spectrometer. $\mathrm{CH}_{3} \mathrm{CN}: \mathrm{H}_{2} \mathrm{O}(75: 25, v / v)$ was used as the mobile phase at $0.2 \mathrm{~mL} / \mathrm{min}$. The ionization source was an ESI interface working in the positive-ion mode. The electrospray voltage was set at $4.5 \mathrm{kV}$, the fragmentor voltage at $150 \mathrm{~V}$ and the drying gas temperature at $300{ }^{\circ} \mathrm{C}$. Nitrogen $(99.5 \%$ purity) was used as nebulizer $(207 \mathrm{kPa})$ and drying gas $(6 \mathrm{~L} / \mathrm{min})$. The scan range was $50-1100 \mathrm{~m} / \mathrm{z}$.

\subsection{Preparation of Crude M. polymorpha Extracts}

Plant material (10 g, fresh weight) was collected from each genotype (WT, Mpcoi1-2 and Mpc1hdz) and oven dried $\left(60^{\circ} \mathrm{C}\right)$ until constant weight. The dry tissue was ground to a fine powder using a Geno/Grinder $(2 \times 2 \mathrm{~min}$ at $2700 \mathrm{rpm})$ and extracted two times at room temperature with $30 \mathrm{~mL}$ of $\mathrm{CHCl}_{3}: \mathrm{MeOH}(2: 1, v / v)$ for at least $6 \mathrm{~h}$ each time. Extracts were combined and concentrated under a nitrogen flow to produce a dark green residue. The remaining solid was dissolved in DMSO to create stock solutions of ca. $90 \mathrm{mg} / \mathrm{mL}$, which were later employed in the bioassays.

\subsection{Chromatographic Fractionation of Extracts}

Plants extracts were prepared as described above starting from ca. $20 \mathrm{~g}$ of plant material and directly subjected to silica gel flash column chromatography employing a solvent polarity gradient starting at $n$-hexane (100\%) up to $\mathrm{AcOEt}: \mathrm{MeOH}(4: 1, v / v)$. A total of 56 metabolite-enriched fractions were obtained. Fractions were analyzed by TLC and those of similar composition were combined to render 12 new pooled fractions, which were screened for antiviral activity.

\subsection{Preparative TLCs}

Photosynthetic metabolites were extracted [two times, o/n, acetone $(30 \mathrm{~mL})$ ] from fresh, finely grounded $M$. polymorpha thallus (ca. $40 \mathrm{~g}$ ). The combined extracts were concentrated to a final volume of $10 \mathrm{~mL}$, centrifuged (4000 rcf), filtrated (45 $\mu \mathrm{m}$, Whatmann PTFE filters) and chromatographed on preparative TLC plates employing the solvent system AcOEt:MeOH (9:1, v/v). Selected fluorescent spots (C, D and E) were scraped off, eluted (AcOEt:MeOH, 4:1, $/ v$ ) and dried under a nitrogen stream. Single components (C, D and E) were prepared at a $10 \mathrm{mg} / \mathrm{mL}$ and submitted to both antiviral assays, as described below, and HPLC-UV-MS analysis as described above.

\subsection{Semisynthetic Preparation of PheoA}

Fresh M. polymorpha thallus (ca. $50 \mathrm{~g}$ ) was oven dried to produce ca. $3.5 \mathrm{~g}$ of dry material, which was ground to a fine powder in the GinoGrinder as described above. The obtained powder ( $3 \mathrm{~g}$ ) was extracted (three times, Acetone, $90 \mathrm{~mL}$ ), the extracts combined and silica gel ( $6 \mathrm{~g}$, ratio 2:1 by weight relative to the dried leaf powder) added. The solvent was evaporated under reduced pressure to produce impregnated silica, which was heated $\left(60{ }^{\circ} \mathrm{C}\right)$ overnight to further potentiate PheoA production. The obtained silica was directly loaded into a flash column that was run as follows: column ID $=3 \mathrm{~cm}$, silica $(70 \mathrm{~g}), n$-hexane: AcOEt (1:1, $300 \mathrm{~mL})$, AcOEt: $\mathrm{MeOH}$ (9:1, $300 \mathrm{~mL} ; 4: 1,600 \mathrm{~mL} ; 7: 3,300 \mathrm{~mL})$, fractions of ca. $35 \mathrm{~mL}$ were collected. Fractions were analyzed by TLC and those containing PheoA were pooled to produce PheoA ( $3.9 \mathrm{mg}, 0.13 \%$ from oven dried leaf material).

Commercial PheoA was purchased from Santa Cruz and dissolved in DMSO at a concentration of $1 \mathrm{mg} / \mathrm{mL}$. Dilutions were prepared directly in the cell culture media at the concentrations described in the figures.

\subsection{Cell Culture}

Vero E6 (ATCC) and Calu3 (ATCC) cell lines were kindly provided by Dr. Enjuanes (CNB-CSIC). A549 cells were kindly provided by Dr. Juan Ortín (CNB-CSIC) and Huh7 cells were kindly provided by Dr. Chisari (TSRI, La Jolla). A549 and Huh7 cells were transduced with a retroviral vector enabling expression of ACE2 in a di-cistronic expression cassette also conferring resistance to blasticidine. Transduced populations were selected 
using $2.5 \mu \mathrm{g} / \mathrm{mL}$ of blasticidine. All cell cultures were kept in complete media (DMEM) supplemented with $10 \mathrm{mM}$ HEPES, $1 \mathrm{X}$ non-essential amino acids (GIBCO), $100 \mathrm{U} / \mathrm{mL}$ penicillin-streptomycin (GIBCO) and $10 \%$ fetal bovine serum (FBS; heat-inactivated at $56^{\circ} \mathrm{C}$ for $30 \mathrm{~min}$ ). Unless otherwise stated, all infection experiments were performed at $37^{\circ} \mathrm{C}$ in a $\mathrm{CO}_{2}$ incubator $\left(5 \% \mathrm{CO}_{2}\right)$ the presence of $2 \% \mathrm{FBS}$ and in the absence of selection antibiotics.

\subsection{Viruses}

SARS-CoV-2 (Coronaviridae; Orthocoronavirinae; Betacoronavirus; Sarbecovirus; strain NL/2020) was kindly provided by Dr. R. Molenkamp, Erasmus University Medical Center Rotterdam. SARS-CoV-2 stocks were produced and titrated in VeroE6 cells by inoculation at a multiplicity of infection (MOI) of $0.001 \mathrm{TCID}_{50} /$ cell. Cell supernatants were harvested at $72 \mathrm{hpi}$, cleared by centrifugation, aliquoted, and stored at $-80^{\circ} \mathrm{C}$. SARS-CoV- 2 virus titers were determined by endpoint dilution and cytopathic effect determination using the tissue culture infective dose fifty $\left(\mathrm{TCID}_{50}\right)$ method by (Reed and Muench, 1938) [41] and expressing the infectivity titers as $\mathrm{TCID}_{50} / \mathrm{mL}$. Additionally, infectivity titers were estimated using endpoint dilutions and immunofluorescence microscopy, as described below. This approach enables determining the number of infectious focus formation unit (FFU) and expressing infectivity as FFU/mL. Both readouts produced comparable SARSCoV-2 infectivity titers and were used to determine optimal virus dose (multiplicity of infection [MOI]; infectious units/cell) for each experiment.

VSV-GFP [42] was kindly provided by Dr. Rodriguez (CNB-CSIC). WNV-GFP recombinant virus was rescued from cloned cDNA as reported previously [43]. Transcomplemented defective reporter HCV virions (HCVtcp) were produced and used as described in Steinmann et al. [44]. The hCoV-229E-GFP [45] was kindly provided by Dr. Thiel (University of Basel) and propagated in Huh7 cells at $33^{\circ} \mathrm{C}$ in a controlled $5 \% \mathrm{CO}_{2}$ environment. GFP-expressing recombinant virus (WNV-GFP, 229E-GFP or VSV-GFP) infectivity was also determined as FFU/mL using endpoint dilution and fluorescence microscopy.

\subsection{Cypopathic Effect Protection Assays in Vero E6 and Huh7-ACE2 Cells}

Vero E6 or Huh7-ACE2 cell monolayers were inoculated $(\mathrm{MOI}=0.001)$ in the presence of a wide range of two-fold dilutions of the crude, or partially purified extracts, or pure compounds and incubated for $72 \mathrm{~h}$. Cytopathic effect and lack thereof was visualized by crystal violet staining, as previously described [17]. Untreated and solvent-treated cells were included in each plate as controls. Assayed samples were pronounced protective when three or more consecutive two-fold serial dilutions (regardless of their final concentration) fully prevented SARS-CoV2-induced antiviral activity as determined by comparison with infected and uninfected control well staining in each experimental plate. A minimum virus dose (10 infectious units/well; MOI 0.001 in 1e4 cells/well) capable of producing overt cytopathic effect was used. Lower virus doses produce visible plaques and complete absence of CPE coincides with the expected endpoint dilution, around 8-fold lower dilutions.

\subsection{Evaluation of the Antiviral Activity by Immunofluorescence Microscopy}

Vero E6, A549-ACE2 or Calu3 were seeded onto 96-well plates as described above and infected in the presence of the indicated compound dose $(\mathrm{MOI}=0.01)$. Twenty-four hours post infection ( $48 \mathrm{~h}$ for Calu3 cells), cells were fixed for $20 \mathrm{~min}$ at room temperature with a $4 \%$ formaldehyde solution in PBS, washed twice with PBS and incubated with incubation buffer (3\% BSA; 0.3\% Triton X100 in PBS) for $1 \mathrm{~h}$. A monoclonal antibody against the $\mathrm{N}$ protein was diluted in the incubation buffer (1:2000, $v / v$; Genetex HL344) and incubated with the cells for $1 \mathrm{~h}$; after this time, cells were washed with PBS and subsequently incubated with a 1:500 $(v / v)$ dilution of a goat anti-rabbit conjugated to Alexa 488 (Invitrogen-Carlsbad, Carlsbad, CA, USA). Nuclei were stained with DAPI (Life Technologies, Budapest, Hungary) as recommended by the manufacturer during 
the secondary antibody incubation. Cells were washed with PBS and imaged using an automated multimode reader Spark Cyto (TECAN-Grödig, Austria).

All the infection experiments were performed by mixing the virus and compound dilutions 1:1 $(v / v)$ before addition to the target cells. In the time-of-addition experiments, Vero E6 cultures were inoculated (MOI from $0.5-1$ ) for $1 \mathrm{~h}$ in the presence or absence of the compounds at $37^{\circ} \mathrm{C}$. Subsequently, virus-compound mixtures were left at all times, or removed and replaced with fresh $2 \%$ FBS complete media containing or not the tested compounds (see experimental scheme in Figure 7 for details). Cells were fixed $6 \mathrm{~h}$ post-inoculation.

\subsection{Viral RNA Quantitation by RT-qPCR}

A549-ACE2 cell monolayers were inoculated at $\mathrm{MOI}=0.001$ in the presence of nontoxic concentrations of the compound. Forty-eight hours later, cell supernatants were collected and heat-inactivated as described in (Smyrlaki et al., 2020) [46], and processed directly for RT-qPCR. Alternatively, cell lysates were prepared using the Trizol reagent (Thermo Scientific) and the viral RNA content was determined by RT-qPCR using previously validated sets of primers and probes specific for the detection of the SARS-CoV-2 E gene and the cellular $18 \mathrm{~S}$ gene, for normalization purposes. $\Delta \mathrm{Ct}$ method was used for relative quantitation of the intracellular viral RNA accumulation in compound-treated cells compared to the levels in infected cells treated with DMSO (set as 100\%). Values obtained in mock-infected cells were used to determine the assay limit of detection (LOD).

\subsection{Cytotoxicity Measurement by MTT Assays}

Cell monolayers were seeded in 96-well plates. The day after cells were treated with a wide range of compound concentrations and forty-eight hours later they were subjected to an MTT assays using standard procedures [47]. The $\mathrm{CC}_{50}$ values were graphically interpolated from dose-response curves obtained with three biological replicates.

\subsection{Assessment of Viral Entry Using Retroviral Pseudotypes}

Retroviral particles pseudotyped with SARS-2-CoV spike envelope protein (SARS2pp) were produced in HEK293T cells as previously described [34] with materials kindly provided by Dr. F. L. Cosset (INSERM, Lyon) and J. M. Casasnovas and J. G. Arriaza (CNBCSIC) for the $S$ protein cDNA. Particles devoid of envelope glycoproteins were produced in parallel as controls.

\subsection{Statitistical Analysis}

Descriptive statistics were calculated using Microsoft Excel. One-way ANOVA and post hoc tests were calculated using IBM SPSS Software Package (version 26). EC 50 and $\mathrm{EC}_{90}$ values were obtained employing the PROBIT regression method [48] using IBM SPSS vs26, except for values in Table 1 that were calculated by graphic interpolation of individual curves.

Synergy analysis was carried out in the web-based platform Synergy Finder (https: / / synergyfinder.fimm.fi/, accessed on 25 September 2021) [29].

\section{Conclusions}

The chlorophyll derivative PheoA, a porphyrin compound similar to the animal Protoporphyrin IX, has an extraordinary antiviral activity against SARS-CoV-2 preventing infection of cultured monkey and human cells, without noticeable cytotoxicity.

PheoA interferes with viral infectivity in a dose- and time-dependent manner.

Besides SARS-CoV-2, PheoA displayed a broad-spectrum antiviral activity against (+) strand RNA viral pathogens such as HCV, West Nile, and other coronaviruses.

Our results indicate that PheoA displays a remarkable potency and a satisfactory therapeutic index, which together with its previous use in photoactivable cancer therapy in humans, suggest that it may be considered as a potential candidate for antiviral therapy against SARS-CoV-2. 
Supplementary Materials: The following are available online at https: / www.mdpi.com/article/ 10.3390/ph14101048/s1, Figure S1: RMDV interferes with SARS-CoV-2-induced cytopathic effect, Figure S2: Crude extracts of several plant species show antiviral potential against SARS-CoV-2 infection in cell culture, Figure S3: TLCs of pooled fractions submitted to antiviral assays, Figure S4: Scheme of PheoA preparation from plant material. KG, Silica gel 60, Figure S5: PheoA protects VeroE6 and human hepatoma Huh7 cells from virus-induced cytopathic effect, Figure S6: Semi-synthetic PheoA preparations display antiviral activity against SARS-CoV-2, Figure S7: Pyropheophorbide a displays antiviral activity against SARS-CoV-2, Figure S8: SARS-CoV-2-pseudotyped retroviral vectors (SARS2pp) are not susceptible to PheoA antiviral activity.

Author Contributions: Conceptualization, G.H.J.-A., U.G., R.S. and P.G.; methodology, G.H.J.-A., V.C., A.L., U.G. and M.G.-R.; validation, G.H.J.-A., A.L., V.C., U.G. and M.G.-R.; formal analysis, G.H.J.-A., A.L., V.C., U.G. and M.G.-R.; investigation, G.H.J.-A., A.L., V.C., U.G., M.G.-R.; data curation, G.H.J.-A.; writing-original draft preparation, G.H.J.-A., R.S. and P.G.; writing-review and editing, G.H.J.-A., U.G., M.G.-R., R.S., P.G.; visualization, G.H.J.-A.; supervision, R.S. and P.G.; funding acquisition, R.S., U.G. and P.G. All authors have read and agreed to the published version of the manuscript.

Funding: This research was funded by CSIC (PIE-RD-COVID-19 ref 202040E236 to R.S., PIE-RDCOVID-19 ref. E202020E079 to P.G. and U.G., and CSIC-CoV19-153 ref PIE-202080E221 to M.G.R.), EVA (European Virus Archive; grant agreement No 871029 to P.G.) and the European UnionNextGenerationEU. G.H.J.-A. was supported by the Deutsche Forschungsgemeinschaft (Individual Research Grant JI 241/2-1).

Institutional Review Board Statement: This research has been approved by our Institutional Ethics Committee.

Informed Consent Statement: Not applicable.

Data Availability Statement: Data is contained within the article.

Acknowledgments: We thank Gema Calvo, Jennifer Moya, Laura Barbado and Enara San Sebastian for outstanding technical assistance. We acknowledge support of the publication fee by the CSIC Open Access Publication Support Initiative through its Unit of Information Resources for Research (URICI).

Conflicts of Interest: The authors declare no conflict of interest.

\section{References}

1. Folegatti, P.M.; Ewer, K.J.; Aley, P.K.; Angus, B.; Becker, S.; Belij-Rammerstorfer, S.; Bellamy, D.; Bibi, S.; Bittaye, M.; Clutterbuck, E.A.; et al. Safety and immunogenicity of the ChAdOx1 nCoV-19 vaccine against SARS-CoV-2: A preliminary report of a phase $1 / 2$, single-blind, randomised controlled trial. Lancet 2020, 396, 467-478. [CrossRef]

2. Grein, J.; Ohmagari, N.; Shin, D.; Diaz, G.; Asperges, E.; Castagna, A.; Feldt, T.; Green, G.; Green, M.L.; Lescure, F.X.; et al. Compassionate use of remdesivir for patients with severe Covid-19. N. Engl. J. Med. 2020, 382, 2327-2336. [CrossRef]

3. Li, X.; Wang, Y.; Agostinis, P.; Rabson, A.; Melino, G.; Carafoli, E.; Shi, Y.; Sun, E. Is hydroxychloroquine beneficial for COVID-19 patients? Cell Death Dis. 2020, 11, 512. [CrossRef]

4. Newman, D.J.; Cragg, G.M. Marine natural products and related compounds in clinical and advanced preclinical trials. J. Nat. Prod. 2004, 67, 1216-1238. [CrossRef]

5. Jan, J.-T.; Cheng, T.-J.R.; Juang, Y.-P.; Ma, H.-H.; Wu, Y.-T.; Yang, W.-B.; Cheng, C.-W.; Chen, X.; Chou, T.-H.; Shie, J.J.; et al. Identification of existing pharmaceuticals and herbal medicines as inhibitors of SARS-CoV-2 infection. Proc. Natl. Acad. Sci. USA 2021, 118, e2021579118. [CrossRef]

6. Gu, C.; Wu, Y.; Guo, H.; Zhu, Y.; Xu, W.; Wang, Y.; Zhou, Y.; Sun, Z.; Cai, X.; Li, Y.; et al. Protoporphyrin IX and verteporfin potently inhibit SARS-CoV-2 infection in vitro and in a mouse model expressing human ACE2. Sci. Bull. 2020, 66, 925-936. [CrossRef] [PubMed]

7. Wachtel-Galor, S.; Benzie, I.F.F. Herbal Medicine: An Introduction to Its History, Usage, Regulation, Current Trends, and Research Needs. In Herbal Medicine: Biomolecular and Clinical Aspects; CRC Press: Boca Raton, FL, USA, 2011.

8. Veeresham, C. Natural products derived from plants as a source of drugs. J. Adv. Pharm. Technol. Res. 2012, 3, 200-201. [CrossRef] [PubMed]

9. Nicolaou, K.C.; Guy, R.K.; Potier, P. Taxoids: New weapons against cancer. Sci. Am. 1996, 274, 94-98. [CrossRef] [PubMed]

10. Efferth, T.; Li, P.C.H.; Konkimalla, V.S.B.; Kaina, B. From traditional Chinese medicine to rational cancer therapy. Trends Mol. Med. 2007, 13, 353-361. [CrossRef]

11. Asakawa, Y.; Ludwiczuk, A. Chemical Constituents of Bryophytes: Structures and Biological Activity. J. Nat. Prod. 2018, 81, 641-660. [CrossRef] 
12. Asakawa, Y.; Ludwiczuk, A.; Nagashima, F. Phytochemical and biological studies of bryophytes. Phytochemistry 2013, 91, 52-80. [CrossRef]

13. Chen, F.; Ludwiczuk, A.; Wei, G.; Chen, X.; Crandall-Stotler, B.; Bowman, J.L. Terpenoid Secondary Metabolites in Bryophytes: Chemical Diversity, Biosynthesis and Biological Functions. Crit. Rev. Plant Sci. 2018, 37, 210-231. [CrossRef]

14. Davies, K.M.; Jibran, R.; Zhou, Y.; Albert, N.W.; Brummell, D.A.; Jordan, B.R.; Bowman, J.L.; Schwinn, K.E. The Evolution of Flavonoid Biosynthesis: A Bryophyte Perspective. Front. Plant Sci. 2020, 11, 7. [CrossRef]

15. Komala, I.; Ito, T.; Nagashima, F.; Yagi, Y.; Asakawa, Y. Cytotoxic, radical scavenging and antimicrobial activities of sesquiterpenoids from the Tahitian liverwort Mastigophora diclados (Brid.) Nees (Mastigophoraceae). J. Nat. Med. 2010, 64, 417-422. [CrossRef]

16. Asakawa, Y.; Ludwiczuk, A.; Hashimoto, T. Cytotoxic and Antiviral Compounds from Bryophytes and Inedible Fungi. J. Pre-Clin. Clin. Res. 2013, 7, 73-85. [CrossRef]

17. Ginex, T.; Garaigorta, U.; Ramírez, D.; Castro, V.; Nozal, V.; Maestro, I.; García-Cárceles, J.; Campillo, N.E.; Martinez, A.; Gastaminza, P.; et al. Host-Directed FDA-Approved Drugs with Antiviral Activity against SARS-CoV-2 Identified by Hierarchical In Silico/In Vitro Screening Methods. Pharmaceuticals 2021, 14, 332. [CrossRef]

18. Wasternack, C.; Hause, B. Jasmonates: Biosynthesis, perception, signal transduction and action in plant stress response, growth and development. An update to the 2007 review in Annals of Botany. Ann. Bot. 2013, 111, 1021-1058. [CrossRef] [PubMed]

19. Monte, I.; Ishida, S.; Zamarreño, A.M.; Hamberg, M.; Franco-Zorrilla, J.M.; García-Casado, G.; Gouhier-Darimont, C.; Reymond, P.; Takahashi, K.; García-Mina, J.M.; et al. Ligand-receptor co-evolution shaped the jasmonate pathway in land plants. Nat. Chem. Biol. 2018, 14, 480-488. [CrossRef] [PubMed]

20. Peñuelas, M.; Monte, I.; Schweizer, F.; Vallat, A.; Reymond, P.; García-Casado, G.; Franco-Zorrilla, J.M.; Solano, R. JasmonateRelated MYC Transcription Factors Are Functionally Conserved in Marchantia polymorpha. Plant Cell 2019, 31, $2491-2509$. [CrossRef] [PubMed]

21. Tanaka, M.; Esaki, T.; Kenmoku, H.; Koeduka, T.; Kiyoyama, Y.; Masujima, T.; Asakawa, Y.; Matsui, K. Direct evidence of specific localization of sesquiterpenes and marchantin A in oil body cells of Marchantia polymorpha L. Phytochemistry 2016, 130, 77-84. [CrossRef] [PubMed]

22. Romani, F.; Banić, E.; Florent, S.N.; Kanazawa, T.; Goodger, J.Q.; Mentink, R.A.; Dierschke, T.; Zachgo, S.; Ueda, T.; Bowman, J.L.; et al. Oil Body Formation in Marchantia polymorpha Is Controlled by MpC1HDZ and Serves as a Defense against Arthropod Herbivores. Curr. Biol. 2020, 30, 2815-2828. [CrossRef]

23. Rolin, D. Control of primary metabolism in plants. Annual Plant Reviews, Volume 22. Ann. Bot. 2006, 98, 1331-1332. [CrossRef]

24. Maeda, H.A. Evolutionary Diversification of Primary Metabolism and Its Contribution to Plant Chemical Diversity. Front. Plant. Sci. 2019, 10, 881. [CrossRef]

25. Ratnoglik, S.L.; Aoki, C.; Sudarmono, P.; Komoto, M.; Deng, L.; Shoji, I.; Fuchino, H.; Kawahara, N.; Hotta, H. Antiviral activity of extracts from Morinda citrifolia leaves and chlorophyll catabolites, Pheophorbide a and pyropheophorbide a, against hepatitis C virus. Microbiol. Immunol. 2014, 58, 188-194. [CrossRef]

26. Asakawa, Y. Biologically active compounds from bryophytes. Pure Appl. Chem. 2007, 79, 557-580. [CrossRef]

27. Chansakaow, S.; Ruangrungsi, N.; Ishikawa, T. Isolation of pyropheophorbide a from the leaves of Atalantia monophylla (ROXB.) CORR. (Rutaceae) as a possible antiviral active principle against herpes simplex virus type 2. Chem. Pharm. Bull. 1996, 44, 1415-1417. [CrossRef] [PubMed]

28. Zhang, H.-J.; Tan, G.T.; Hoang, V.D.; Hung, N.V.; Cuong, N.M.; Soejarto, D.D.; Pezzuto, J.M.; Fong, H.H. Natural anti-HIV agents. Part IV. Anti-HIV constituents from Vatica cinerea. J. Nat. Prod. 2003, 66, 263-268. [CrossRef] [PubMed]

29. Ianevski, A.; Giri, A.K.; Aittokallio, T. SynergyFinder 2.0: Visual analytics of multi-drug combination synergies. Nucleic Acids Res. 2020, 48, W488-W493. [CrossRef]

30. Bouslama, L.; Hayashi, K.; Lee, J.-B.; Ghorbel, A.; Hayashi, T. Potent virucidal effect of Pheophorbide a and pyropheophorbide a on enveloped viruses. J. Nat. Med. 2011, 65, 229-233. [CrossRef] [PubMed]

31. Xodo, L.E.; Rapozzi, V.; Zacchigna, M.; Drioli, S.; Zorzet, S. The chlorophyll catabolite Pheophorbide a as a photosensitizer for the photodynamic therapy. Curr. Med. Chem. 2012, 19, 799-807. [CrossRef]

32. Ohta, S.; Ono, F.; Shiomi, Y.; Nakao, T.; Aozasa, O.; Nagate, T.; Kitamura, K.; Yamaguchi, S.; Nishi, M.; Miyata, H. Anti-Herpes Simplex Virus substances produced by the marine green alga, Dunaliella primolecta. J. Appl. Phycol. 1998, 10, 349-356. [CrossRef]

33. Hoffmann, M.; Kleine-Weber, H.; Schroeder, S.; Krüger, N.; Herrler, T.; Erichsen, S.; Schiergens, T.S.; Herrler, G.; Wu, N.-H.; Nitsche, A.; et al. SARS-CoV-2 Cell Entry Depends on ACE2 and TMPRSS2 and Is Blocked by a Clinically Proven Protease Inhibitor. Cell 2020, 181, 271-280.e8. [CrossRef] [PubMed]

34. García-Arriaza, J.; Garaigorta, U.; Pérez, P.; Lázaro-Frías, A.; Zamora, C.; Gastaminza, P.; del Fresno, C.; Casasnovas, J.M.; Sorzano, C.Ó.S.; Esteban, M.; et al. COVID-19 vaccine candidates based on modified vaccinia virus Ankara expressing the SARS-CoV-2 spike induce robust T- and B-cell immune responses and full efficacy in mice. J. Virol. 2021, 95. [CrossRef] [PubMed]

35. RÖder, B.; Hanke, T.H.; Oelckers, S.T.; Hackbarth, S.; Symietz, C.H. Photophysical properties of Pheophorbide a in solution and in model membrane systems. J. Porphyr. Phthalocyanines 2000, 4, 37-44. [CrossRef]

36. Lebedeva, N.S.; Gubarev, Y.A.; Koifman, M.O.; Koifman, O.I. The Application of Porphyrins and Their Analogues for Inactivation of Viruses. Molecules 2020, 25, 4368. [CrossRef] 
37. Bellnier, D.A.; Greco, W.R.; Loewen, G.M.; Nava, H.; Oseroff, A.R.; Dougherty, T.J. Clinical pharmacokinetics of the PDT photosensitizers porfimer sodium (Photofrin), 2-[1-hexyloxyethyl]-2-devinyl pyropheophorbide-a (Photochlor) and 5-ALAinduced protoporphyrin IX. Lasers Surg. Med. 2006, 38, 439-444. [CrossRef]

38. Yilmaz, C.; Gökmen, V. Chlorophyll. In Encyclopedia of Food and Health; Elsevier: Amsterdam, The Netherlands, 2016 ; pp. 37-41.

39. Saide, A.; Lauritano, C.; Ianora, A. Pheophorbide a: State of the Art. Marine Drugs 2020, 18, 257. [CrossRef]

40. Hajri, A.; Wack, S.; Meyer, C.; Smith, M.K.; Leberquier, C.; Kedinger, M.; Aprahamian, M. In Vitro and In Vivo Efficacy of Photofrin ${ }^{\circledR}$ and Pheophorbide a, a Bacteriochlorin, in Photodynamic Therapy of Colonic Cancer Cells. Photochem. Photobiol. 2002, 75, 140-148. [CrossRef]

41. Lei, C.; Yang, J.; Hu, J.; Sun, X. On the Calculation of TCID 50 for Quantitation of Virus Infectivity. Virol. Sin. 2021, 36, 141-144. [CrossRef]

42. Ostertag, D.; Hoblitzell-Ostertag, T.M.; Perrault, J. Overproduction of double-stranded RNA in vesicular stomatitis virus-infected cells activates a constitutive cell-type-specific antiviral response. J. Virol. 2007, 81, 503-513. [CrossRef]

43. Pierson, T.C.; Diamond, M.S.; Ahmed, A.A.; Valentine, L.E.; Davis, C.W.; Samuel, M.A.; Hanna, S.L.; Puffer, B.A.; Doms, R.W. An infectious West Nile virus that expresses a GFP reporter gene. Virology 2005, 334, 28-40. [CrossRef] [PubMed]

44. Steinmann, E.; Brohm, C.; Kallis, S.; Bartenschlager, R.; Pietschmann, T. Efficient trans-encapsidation of hepatitis C virus RNAs into infectious virus-like particles. J. Virol. 2008, 82, 7034-7046. [CrossRef] [PubMed]

45. Cervantes-Barragan, L.; Züst, R.; Maier, R.; Sierro, S.; Janda, J.; Levy, F.; Speiser, D.; Romero, P.; Rohrlich, P.S.; Ludewig, B.; et al. Dendritic cell-specific antigen delivery by coronavirus vaccine vectors induces long-lasting protective antiviral and antitumor immunity. MBio 2010, 1, 227. [CrossRef] [PubMed]

46. Smyrlaki, I.; Ekman, M.; Lentini, A.; de Sousa, N.R.; Papanicolaou, N.; Vondracek, M.; Aarum, J.; Safari, H.; Muradrasoli, S.; Rothfuchs, A.G.; et al. Massive and rapid COVID-19 testing is feasible by extraction-free SARS-CoV-2 RT-PCR. Nat. Commun. 2020, 11, 4812. [CrossRef] [PubMed]

47. Mosmann, T. Rapid colorimetric assay for cellular growth and survival: Application to proliferation and cytotoxicity assays. J. Immunol. Methods 1983, 65, 55-63. [CrossRef]

48. Cleophas, T.J.; Zwinderman, A.H. Machine Learning in Medicine-A Complete Overview; Cleophas, T.J., Zwinderman, A.H., Eds.; Springer International Publishing: Cham, Switzerland, 2020; pp. 347-354. 